\title{
Vitamin D and COVID-19 infection; recent findings
}

\author{
Alireza Pouramini ${ }^{1}$, Fatemeh Kafi ${ }^{1}$, Shakiba Hassanzadeh ${ }^{2 *}$ \\ Abstract \\ COVID-19 infection increases the risk of death in patients with chronic conditions such as diabetes or obesity. The exact role of vitamin \\ $\mathrm{D}$ in COVID-19 infection is unknown and controversial. Furthermore, the exact prevalence of vitamin $\mathrm{D}$ deficiency is still unknown but \\ it affects individuals worldwide regardless of ethnicity and age. Herein, we give an overview of vitamin D deficiency as a global public \\ health problem, the role of vitamin D in COVID-19 infection, and the proper approach to treating vitamin D deficiency. \\ Keywords: COVID-19, Vitamin D, SARS-CoV-2, Immune system, Vitamin D \\ Citation: Pouramini A, Kafi F, Hassanzadeh S. Vitamin D and COVID-19 infection; recent findings. J Renal Endocrinol. 2021;7:e19. doi: \\ 10.34172/jre.2021.19. \\ Copyright $(\odot 2021$ The Author(s); Published by Nickan Research Institute. This is an open-access article distributed under the terms of \\ the Creative Commons Attribution License (http://creativecommons.org/licenses/by/4.0), which permits unrestricted use, distribution, and \\ reproduction in any medium, provided the original work is properly cited.
}

\section{Introduction}

The severe acute respiratory syndrome coronavirus type2 (SARS-CoV-2) coronavirus disease 2019 (COVID-19) has rapidly spread worldwide. The severity of COVID-19 infection ranges from asymptomatic to severe and may lead to acute respiratory distress syndrome or multi-organ failure. Therefore, the interest in improving the immune system to avoid COVID-19 infection in this devastating pandemic has increased (1).

COVID-19 infection exacerbates the inflammatory response and increases the risk of death in patients with chronic conditions. For example, in diabetic patients, which causes systemic inflammation, worse infectionrelated respiratory symptoms are more likely to develop (2). Obesity and central adiposity are also significant risk factors for COVID-19-related complications, especially in those with compromised heart and lung functions (3). The risk of COVID-19-associated thrombotic complications is also increased due to common vascular damages in diabetic and hypertensive patients (4).

Several preventive measures for general public health have been recommended to limit the risk of SARS-CoV-2 transmission including hand and respiratory cleanliness (5). A healthy lifestyle and proven-effective nutraceutical supplements may help combat some aspects of the infection. Currently, it is critical to provide preventative health measures to lower the risk of COVID-19 infection including proper vaccine distribution and/or effective antiviral medicine.

Adequate nutrition and eating habits have been widely discussed during the COVID-19 pandemic, since underestimating the importance of nutrition in COVID-19 patients will significantly impact their prognosis. This is because of their impact on noncommunicable diseases (such as diabetes and obesity) that can result in more severe infections and also their role in the improvement of the patients' inflammatory state (6). In addition, vitamins C and D and zinc (7) have been reported to possibly have an important role in the susceptibility to the disease and the function maintenance of the immune system (8). C-reactive protein (CRP) and other inflammatory markers, including inflammatory cytokines and chemokines, are commonly high in patients with COVID-19 (9, 10). Therefore, any nutritional method that can regulate the immune function may be advantageous both early on, when an adequate immune response is critical, and later on, when a cytokine storm may cause hyper-reactive immune responses.

In this review, we give an overview of vitamin $\mathrm{D}$ deficiency as a global public health problem, the role of vitamin D in COVID-19 infection, and the proper approach to treating vitamin $\mathrm{D}$ deficiency.

\section{Search strategy}

For this mini-review, we searched PubMed/Medline, Web of Science, Scopus, DOAJ (Directory of Open Access Journals), Embase, and Google Scholar, using keywords including; COVID-19, vitamin D, SARS-CoV-2 and immune system

Vitamin D as a global public health problem

Vitamin D, a fat-soluble vitamin, is essential in calcium homeostasis and bone health. It has also been associated with different disorders such as hypertension, diabetes, metabolic syndrome, cancer, autoimmune, and infectious illnesses (11). These conditions have a significant impact 


\section{Implication for health policy/practice/research/ medical education}

COVID-19 infection increases the risk of death in patients with chronic conditions such as diabetes or obesity. The exact role of vitamin D in COVID-19 infection is unknown and controversial.

on global public health.

The exact prevalence of vitamin $\mathrm{D}$ deficiency is still unknown but it is estimated that it affects around one billion people worldwide regardless of ethnicity and age. Interestingly, vitamin $\mathrm{D}$ deficiency may be seen in some low-latitude or industrialized countries. Traditionally, in low-latitude countries, it was considered that the ultraviolet B radiation is sufficient to prevent vitamin D deficiency and in industrialized countries, fortification of vitamin D has been performed for several years (11).

\section{Vitamin D role in COVID-19}

Our lungs have about a $70 \mathrm{~m}^{2}$ surface area that is in contact with air, so it is a significant target for viruses like SARS-CoV-2. Vitamin D may have several roles in COVID-19 infection. For example, vitamin D deficiency can impair innate cellular immunity and trigger cytokine storms, which contribute to the development of ARDSassociated COVID-19. Additionally, vitamin D promotes the production of antimicrobial peptides in the respiratory epithelium, which makes viral infections and COVID-19 symptoms unlikely. Vitamin D may also have an antiinflammatory effect on the body when it is exposed to SARS-CoV-2 infection $(12,13)$. Covid-19 is characterized by the dysregulation of this response, particularly the renin-angiotensin system, and the level of over-activation of this system is associated with a poorer prognosis.

The CYP27B1 enzyme converts vitamin $25(\mathrm{OH}) \mathrm{D}$ to its active form in antigen-presenting cells (APCs) such as dendritic cells (DCs) and macrophages (14). Similar to macrophages and DCs, endothelial cells display major histocompatibility complex class I and II antigens and may function as APCs (15). They play an important role in vitamin $\mathrm{D}$ function in innate and adaptive immunity.

\section{Treatment of vitamin D deficiency}

The amount of vitamin $\mathrm{D}$ is measured by the blood vitamin D. However, we are unsure about the optimal doses of vitamin D. Some evidence support $50 \mathrm{nmol} / \mathrm{L}$ vitamin $25(\mathrm{OH}) \mathrm{D}$ levels because parathyroid hormone does not significantly decrease in individuals with vitamin $\mathrm{D}$ baseline levels more than $50 \mathrm{nmol} / \mathrm{L}$. A study with 365,530 participants found that the $45-60 \mathrm{nmol} / \mathrm{L}$ range is an excellent target for decreasing mortality and premature death $(16,17)$. A 2017 meta-analysis found that individuals who took vitamin $\mathrm{D}$ daily or weekly without bolus doses had higher protective effects than those who took one or more bolus doses (18). Similarly, a placebocontrolled study of 3046 infants given 100000 IU vitamin
D bolus doses every three months found no reduction in the incidence of pneumonia and there were even increased incidences in certain cases (19). Bolus vitamin D3 supplements, or even high doses of 4000 IU/day or $10000 \mathrm{IU} /$ day, may have produced worse results in bone mineral density than $400 \mathrm{IU} /$ day because the transiently high level of vitamin D activated the 24-hydroxylase enzyme, resulting in the production of $24,25(\mathrm{OH}) 2 \mathrm{D}$, an inactive form of vitamin D $(20,21)$.

Even in obese individuals, regular doses of 800 IU are sufficient to achieve the target of a minimum concentration of $50 \mathrm{nmol} / \mathrm{L}$ vitamin $\mathrm{D}$, and since doses up to $4000 \mathrm{IU} /$ day are safe and vitamin $\mathrm{D}$ capsules are typically sold in $1000 \mathrm{IU}$ capsules forms, the use of one $1000 \mathrm{IU}$ capsule per day is sufficient and safe for all adults (22).

Meta-analysis regarding vitamin D association with COVID-19 disease

A meta-analysis of 373 critical COVID-19 patients that was published in 2020 found that patients with worse prognoses had significantly lower serum levels of vitamin D compared to those with favorable prognoses (23). In addition, another meta-analysis that included 532 patients from two randomized controlled trials (RCTs) and one retrospective case-control research found that patients who took vitamin $\mathrm{D}$ supplements required less intensive care unit (ICU) admission (24). On the contrary, Rawat et al conducted a meta-analysis of three randomized controlled trials and two quasi-experimental studies to determine the effect of vitamin $\mathrm{D}$ supplementation in COVID-infected individuals. They reported that vitamin $\mathrm{D}$ supplementation did not significantly reduce the mortality and ICU admission rates, or the need for invasive ventilation (25).

The key reasons for the various findings may be as the followings; 1) Currently, there are limited available clinical trials and inadequate information about the influence of the various doses of vitamin D as well as the proper duration of therapy on the outcome. 2) Additionally, the current studies lack the sufficient information to examine the effect of vitamin D therapy in patients with severe vitamin $\mathrm{D}$ deficiency at baseline. 3) The characteristics of the participants of these studies that had comorbid conditions were heterogeneous making the evaluation of vitamin $\mathrm{D}$ effect in these individuals impossible due to insufficient available evidence.

As a result, more RCTs with enough sample sizes are required to fill these limitations.

Authors' contribution

AP and FK wrote the draft. SH conducted the English and scientific edit. All authors read and signed the final draft.

Conflicts of interest

The authors declare that they have no competing interests.

Ethical considerations

Ethical issues (including plagiarism, data fabrication, double 
publication) have been completely observed by the authors.

Funding/Support

None.

\section{References}

1. Watkins J. Preventing a covid-19 pandemic. BMJ. 2020;368:m810. doi: 10.1136/bmj.m810.

2. Gupta R, Hussain A, Misra A. Diabetes and COVID-19: evidence, current status and unanswered research questions. Eur J Clin Nutr. 2020;74:864-70. doi: 10.1038/s41430-0200652-1.

3. Wu Z, McGoogan JM. Characteristics of and Important Lessons From the Coronavirus Disease 2019 (COVID-19) Outbreak in China: Summary of a Report of 72314 Cases From the Chinese Center for Disease Control and Prevention. JAMA. 2020;323:1239-42. doi: 10.1001/jama.2020.2648.

4. WHO Coronavirus (COVID-19) Dashboard -- WHO Coronavirus (COVID-19) Dashboard With Vaccination Data [Internet]. Available from: https://covid19.who.int/.

5. Li Q, Guan X, Wu P, Wang X, Zhou L, Tong Y, et al. Early Transmission Dynamics in Wuhan, China, of Novel Coronavirus-Infected Pneumonia. N Engl J Med. 2020;382:1199-207. doi: 10.1056/NEJMoa2001316.

6. Chaplin DD. Overview of the immune response. J Allergy Clin Immunol. 2010;125:S3-23. doi: 10.1016/j.jaci.2009.12.980.

7. Zabetakis I, Lordan R, Norton C, Tsoupras A. COVID-19: The Inflammation Link and the Role of Nutrition in Potential Mitigation. Nutrients. 2020;12. doi: 10.3390/nu12051466.

8. Maggini S, Beveridge S, Sorbara PJP, Senatore G. Feeding the immune system: the role of micronutrients in restoring resistance to infections. Cab Reviews: Perspectives in Agriculture, Veterinary Science, Nutrition and Natural Resources. 2008;3:1-21.

9. Herold T, Jurinovic V, Arnreich C, Lipworth BJ, Hellmuth JC, von Bergwelt-Baildon M, et al. Elevated levels of IL-6 and CRP predict the need for mechanical ventilation in COVID-19. J Allergy Clin Immunol. 2020;146:128-36.e4. doi: 10.1016/j. jaci.2020.05.008.

10. Wu C, Chen X, Cai Y, Xia J, Zhou X, Xu S, et al. Risk Factors Associated With Acute Respiratory Distress Syndrome and Death in Patients With Coronavirus Disease 2019 Pneumonia in Wuhan, China. JAMA Intern Med. 2020;180:934-43. doi: 10.1001/jamainternmed.2020.0994.

11. Holick MF, Chen TC. Vitamin D deficiency: a worldwide problem with health consequences. Am J Clin Nutr. 2008;87:1080s-6s. doi: 10.1093/ajcn/87.4.1080S.

12. Daneshkhah A, Agrawal V, Eshein A, Subramanian H, Roy HK, Backman V. Evidence for possible association of vitamin D status with cytokine storm and unregulated inflammation in COVID-19 patients. Aging Clin Exp Res. 2020;32:2141-58. doi: 10.1007/s40520-020-01677-y.

13. Mitchell F. Vitamin-D and COVID-19: do deficient risk a poorer outcome? Lancet Diabetes Endocrinol. 2020;8:570. doi: 10.1016/s2213-8587(20)30183-2.

14. Bikle DD. Vitamin D metabolism, mechanism of action, and clinical applications. Chem Biol. 2014;21:319-29. doi: 10.1016/j.chembiol.2013.12.016.

15. Virzì GM, Zhang J, Nalesso F, Ronco C, McCullough PA. The Role of Dendritic and Endothelial Cells in Cardiorenal Syndrome. Cardiorenal Med. 2018;8:92-104. doi: 10.1159/000485937.

16. Griffin G, Hewison M, Hopkin J, Kenny R, Quinton R, Rhodes J, et al. Vitamin D and COVID-19: evidence and recommendations for supplementation. R Soc Open Sci. 2020;7:201912. doi: 10.1098/rsos.201912.

17. Fan X, Wang J, Song M, Giovannucci EL, Ma H, Jin G, et al. Vitamin D Status and Risk of All-Cause and Cause-Specific Mortality in a Large Cohort: Results From the UK Biobank. J Clin Endocrinol Metab. 2020;105. doi: 10.1210/clinem/ dgaa432.

18. Martineau AR, Jolliffe DA, Hooper RL, Greenberg L, Aloia JF, Bergman P, et al. Vitamin D supplementation to prevent acute respiratory tract infections: systematic review and metaanalysis of individual participant data. BMJ. 2017;356:i6583. doi: 10.1136/bmj.i6583.

19. Manaseki-Holland S, Maroof Z, Bruce J, Mughal MZ, Masher MI, Bhutta ZA, et al. Effect on the incidence of pneumonia of vitamin D supplementation by quarterly bolus dose to infants in Kabul: a randomised controlled superiority trial. Lancet. 2012;379:1419-27. doi: 10.1016/s0140-6736(11)61650-4.

20. Ketha H, Thacher TD, Oberhelman SS, Fischer PR, Singh RJ, Kumar R. Comparison of the effect of daily versus bolus dose maternal vitamin $\mathrm{D}(3)$ supplementation on the 24,25-dihydroxyvitamin $\mathrm{D}(3)$ to 25 -hydroxyvitamin $\mathrm{D}(3)$ ratio. Bone. 2018;110:321-5. doi: 10.1016/j.bone.2018.02.024.

21. Burt LA, Billington EO, Rose MS, Raymond DA, Hanley DA, Boyd SK. Effect of High-Dose Vitamin D Supplementation on Volumetric Bone Density and Bone Strength: A Randomized Clinical Trial. JAMA. 2019;322:736-45. doi: 10.1001/ jama.2019.11889.

22. Griffin G, Hewison M, Hopkin J, Kenny RA, Quinton R, Rhodes J, et al. Preventing vitamin D deficiency during the COVID-19 pandemic: UK definitions of vitamin D sufficiency and recommended supplement dose are set too low. Clin Med (Lond). 2021;21:e48-e51. doi: 10.7861/clinmed.2020-0858.

23. Munshi R, Hussein MH, Toraih EA, Elshazli RM, Jardak C, Sultana N, et al. Vitamin D insufficiency as a potential culprit in critical COVID-19 patients. J Med Virol. 2021;93:733-40. doi: 10.1002/jmv.26360.

24. Shah K, Saxena D, Mavalankar D. Vitamin D supplementation, COVID-19 and disease severity: a meta-analysis. Qjm. 2021;114:175-81. doi: 10.1093/qjmed/hcab009.

25. Rawat D, Roy A, Maitra S, Shankar V, Khanna P, Baidya DK. "Vitamin D supplementation and COVID-19 treatment: A systematic review and meta-analysis". Diabetes Metab Syndr. 2021;15:102189. doi: 10.1016/j.dsx.2021.102189. 